\title{
O voltarredondense e sua contribuição no processo de gestão ambiental pública
}

\author{
The voltarredondense and its contribution to public environmental \\ management process
}

\section{Francisco Jácome Gurgel Júnior gurgel.jr@gmail.com}

Docente do Centro Universitário de Volta Redonda - UniFOA; Docente da Secretaria Estadual de Educação do Rio de Janeiro/ SEEDUC-RJ

\section{RESUMO}

O objeto da pesquisa em tela é a investigação e discussão acerca da participação da sociedade no processo de gestão ambiental pública, com ênfase no município de Volta Redonda/RJ. Pretende-se, secundariamente, identificar e relacionar todas as formas existentes de se garantir essa preciosa prerrogativa aos munícipes voltarredondenses, para que eles tenham conhecimento e/ou interesse na questão ambiental local, suas peculiaridades e ciência das formas, como maneira de se garantir sua efetiva participação na gestão ambiental. Fomentar e sensibilizar a população voltarredondense para sua participação efetiva é tarefa árdua e demorada, pois a maioria absoluta da sociedade tem baixa percepção acerca dos problemas ambientais locais que afetam sua qualidade de vida e os recursos naturais existentes e que eventualmente, são impactados negativamente pela fragilidade e ineficiência do Poder Público Municipal, pelos infratores ambientais e pelo desconhecimento da legislação ambiental vigente. A omissão dessa mesma sociedade que desconhece os instrumentos legais de gestão ambiental e os processos de adesão e participação gera prejuízos consideráveis a todos, pois o engajamento comunitário é condição indispensável para o alcance da sustentabilidade local, por meio de uma gestão ambiental municipal descentralizada, democrática e compartilhada que integre os agentes públicos encarregados dessa missão e os cidadãos, na busca de seu aperfeiçoamento e de cidades mais sustentáveis.

\section{Palavras-chave}

Participação; sociedade; gestão ambiental pública; Volta Redonda / RJ.

\begin{abstract}
The screen object of research is the research and discussion about the participation of society in public environmental management process, emphasizing the city of Volta Redonda / RJ. It is intended secondarily identify and list all the existing ways to ensure this precious prerogative to voltarredondenses citizens so that they have knowledge and / or interest in local environmental issue, its peculiarities and science of the ways to ensure their effective participation in environmental management. Encourage and sensitize the voltarredondense population for effective participation is arduous and time consuming task because the absolute majority of society has low awareness about local environmental problems that affect their quality of life and natural resources and possibly being negatively impacted by the weakness and inefficiency of the Municipal Government, the environmental offenders and the lack of environmental regulations. The omission of this same society that is unaware of the legal instruments for environmental management and compliance processes and participation generates considerable damage to all, since community engagement is an indispensable condition for achieving local sustainability through decentralized municipal environmental management, democratic and shared that integrates public officials in charge of this mission and citizens in the search for improvement and more sustainable cities.
\end{abstract}

\section{Keywords}

Participation, Society, Public Environmental Management, Volta Redonda / RJ.

\section{Como você deve citar?}

GURGEL JÚNIOR, Francisco Jácome. O voltarredondense e sua contribuição no processo de gestão ambiental pública. Cadernos UniFOA, Volta Redonda, n. 32, p. 67-78, dez., 2016. 


\section{INTRODUÇÃO}

Machado (2010) acredita que a participação popular, visando à conservação do meio ambiente, insere-se num quadro mais amplo da participação diante dos interesses difusos e coletivos da sociedade, sendo uma das notas características da segunda metade do século XX. A participação popular dá-se no processo legislativo (iniciativa popular e referendo) e em órgãos colegiados dotados de poderes normativos (como o Conselho Nacional de Meio Ambiente); na formulação e execução de políticas ambientais (em que se destaca a discussão do Estudo de Impacto Ambiental e o plebiscito); e no acesso ao Poder Judiciário (em que merecem relevo a ação direta de inconstitucionalidade, a ação civil pública, a ação popular, o mandado de segurança e o mandado de injunção). A participação não se restringe à tomada de conhecimento do plano pela população, mas estende-se à capacidade de decidir a respeito do plano, com poder modificá-lo e reformulá-lo. Santos (2004) defende que participar, em planejamento, significa tomar parte, integrar-se pela razão ou pelo sentimento, fazer saber, saber comunicar, reconhecer diferentes interesses, expectativas e valores, identificar analogias, debater, negociar, evidenciar pontos comuns, definir interesses, promover alianças, promover ajustes e tomar decisões de consenso sobre aquilo que é de uso ou do direito de todos, na presença de todos. A audiência pública é um exemplo típico de garantia da participação popular no processo de licenciamento ambiental e avaliação de impacto ambiental, referido na resolução CONAMA $n^{\circ}$ 001/86 e que implica na administração dos conflitos oriundos das divergências de interesse entre os agentes sociais envolvidos no processo. Sua realização acontece após a execução do Estudo de Impacto Ambiental (EIA) e apresentação do respectivo relatório de impacto ao meio ambiente (RIMA).

Segundo Buarque (2002), o poder local é, assim, ao mesmo tempo, a essência da democracia e da participação pela escala dos problemas e da organização da sociedade e a configuração das estruturas de poder conservadoras e autoritárias, pelo jogo de compromissos e vinculações oligárquicas. Milaré (2009) ressalta que a gestão democrática da cidade não será completa se não estiverem incluídos, nesse processo, os interesses e as necessidades das aglomerações urbanas, dentro das quais se inserem os Municípios. Philippi Jr. et al (2004) definem que o conceito de participação refere-se principalmente à participação direta dos cidadãos nos processos decisórios. Essas decisões podem dizer respeito à organização do espaço urbano, à construção de obras públicas de infraestrutura, de equipamentos sociais urbanos ou de habitações, e mesmo, aspectos administrativos ou de prestação de serviços públicos. Saboya (2006) salienta que a participação popular é imprescindível, não apenas por força do Estatuto da Cidade, mas por uma necessidade de garantir representatividade ao Plano Diretor e de forma que não seja associada a esta ou àquela gestão, conforme observado na figura 01.

Figura 1 - 0 gráfico acima ilustra os fatores que demonstram e orientam a participação pública no processo de formulação de políticas públicas.

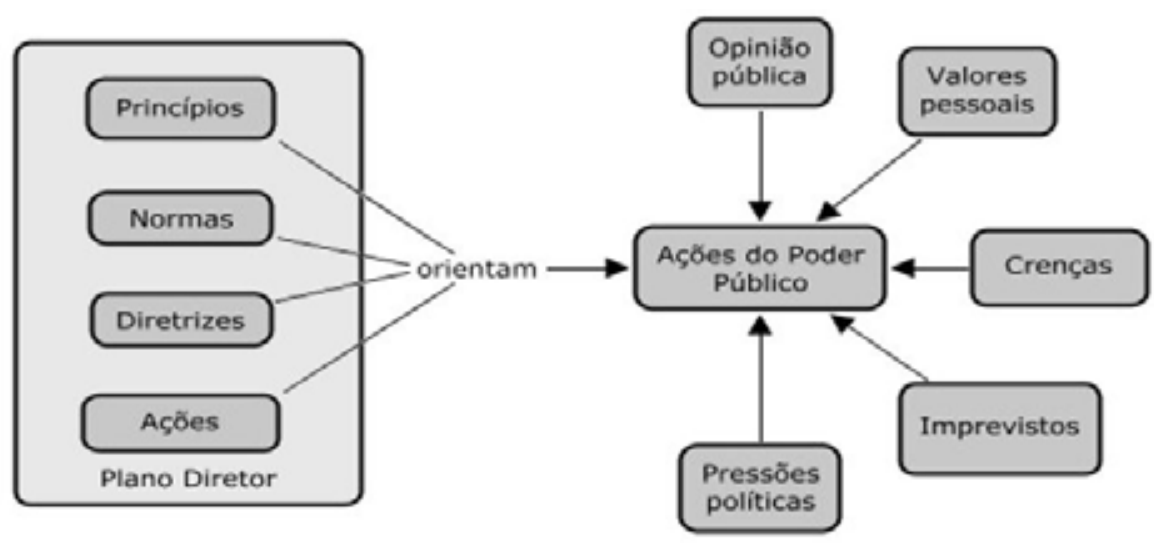

Fonte: Saboya, 2006. 


\section{REVISÃO BIBLIOGRÁFICA}

A gestão ambiental é um ramo da Administração que trata do modo como uma organização gerencia suas atividades em relação ao ambiente. Sob o ponto de vista governamental, é a condução, direção e controle pelo governo do uso dos recursos naturais, por meio de seus instrumentos formais como as leis, regulamentos, taxas, tributação, etc. A utilização de ferramentas deve ser acompanhada de uma atitude humana de humildade e capacidade de negociação, como nunca antes havia sido exigido. Destarte, a atuação e consolidação do Sistema Municipal de Meio Ambiente é de importância fundamental para a preservação e/ou conservação do meio ambiente urbano, utilizando-se da fiscalização ambiental, do licenciamento ambiental, do monitoramento ambiental e da educação ambiental, conforme previsto na lei da Política Nacional de Meio Ambiente.

A simples existência de um Sistema Municipal de Meio Ambiente (SISMUMA) não configura a efetiva gestão dos recursos ambientais dos municípios, tampouco garante que ele esteja agindo com sinergia e em consonância com os objetivos inicialmente traçados. A Secretaria Municipal de Meio Ambiente, definida pelo Sistema Nacional de Meio Ambiente (SISNAMA - Lei n 6.938/81) como órgão ou entidade local é que deve se responsabilizar pela gerência, controle e fiscalização de todas as atividades que contemplem a proteção ao meio ambiente, respeitadas as suas respectivas jurisdições.

0 artigo 23 da Constituição Federal de 1988 enumera as competências materiais comuns da União, Estados, Distrito Federal e Municípios, destacando-se a proteção ao meio ambiente, combate à poluição em qualquer das suas formas e a preservação das florestas, fauna e flora. Dallari (2002) acrescenta que o Brasil nasceu no município e, durante os primeiros séculos da história brasileira, todos os problemas de interesse comunitário eram resolvidos pela iniciativa particular ou pelo governo municipal, que acabou assumindo grande importância por ser o governo efetivamente presente.

A descentralização da gestão ambiental é imprescindível para o êxito da difícil e complexa tarefa de minimizar e/ou mitigar os efeitos desastrosos da ação antrópica sobre a biosfera que integra e circunda o meio urbano, exercendo a fiscalização, controle e licenciamento (Lei Federal n 9.605/98 - Crimes Ambientais) das atividades potencialmente poluidoras no âmbito municipal. Nesse sentido, é condição sine qua non o fortalecimento do órgão municipal, a qualificação de seu corpo técnico, sua autonomia e cooperação com o órgão executor (Instituto Brasileiro do Meio Ambiente e dos Recursos Naturais Renováveis/IBAMA) e seccional Instituto Estadual do Ambiente (INEA), visando à potencialização das ações de fiscalização e à busca da compatibilização da preservação da natureza com o crescimento urbano.

É imprescindível para os citadinos a atuação responsável do órgão ambiental municipal, no sentido de gerir os recursos naturais existentes e vitais para a boa qualidade de vida dos munícipes, controlando e fiscalizando o ar, as águas, os resíduos e as áreas verdes. Nesse ínterim, destaca-se a gestão ambiental exercida pelo Poder Público Municipal como importante ferramenta de controle e garantia de perenidade dos recursos naturais, aperfeiçoando os sistemas de fiscalização e fomentando a participação popular no processo de gestão. Os municípios devem implementar a sua Política Urbana, conforme explícito na Lei Federal $n^{\circ} 10.257 / 01$, art. 1. ${ }^{\circ}$, em seu parágrafo único, que estabelece "normas de ordem pública e interesse social que regulam o uso da propriedade urbana em prol do bem coletivo, da segurança e do bem-estar dos cidadãos, bem como do equilíbrio ambiental".

Elencar as políticas e instrumentos de gestão ambiental urbana, identificar suas respectivas áreas de atuação e medir a efetividade de seu controle e fiscalização é indispensável para se aperfeiçoar o Sistema Municipal de Meio Ambiente, identificando suas fragilidades e propondo medidas corretivas pontuais. Ter uma Política Urbana eficiente é garantir um processo contínuo voltado para a melhoria 
constante da qualidade de vida das nossas cidades. Milaré (2009) ressalta que o município é um ente federado, entre tantos outros Municípios e Estados que constituem a República Federativa do Brasil e que jamais poderá se desenvolver sozinho, embora tenha de ocupar-se dos seus peculiares interesses. Primar por uma gestão ambiental urbana eficiente é responsabilidade compartilhada entre o Poder Público, empresas, terceiro setor e, principalmente, a sociedade residente, estabelecendo um fórum de discussões constante que esteja atento às demandas locais, deliberando sobre elas e exigindo respostas rápidas em prol da proteção do meio ambiente.

As questões do meio ambiente imprimem uma amplitude de comportamento humano mais complexo, pois demandam cuidados na prevenção de impactos negativos, sobretudo ao se focalizar o desenvolvimento regional e urbano. É crescente o número de municípios que despertam para a necessidade de criar e fortalecer a sua área de meio ambiente. Isso representa um avanço. Porém, ainda continua bastante grande o contingente daqueles que não possuem sequer um departamento relacionado a essa área. 0 diagnóstico Perfil dos Municípios Brasileiros, Meio Ambiente, realizado pelo Instituto Brasileiro de Geografia e Estatística (IBGE), mostra que a realidade ainda está distante da meta de ter o SISNAMA em pleno funcionamento. A grande maioria dos municípios $(77,8 \%)$ não tem conselhos de meio ambiente ativos. Isso se aplica também aos fundos municipais de meio ambiente $(93,4 \%)$ e à existência de uma legislação adaptada às condições locais (IBGE, 2008).

Silva (2004) propõe a classificação a seguir apresentada (Quadro 1) para os instrumentos de implementação e execução da política florestal que possuem semelhança com os instrumentos adotados pelos municípios na execução de sua política ambiental local.

Quadro 1 - Instrumentos Legais, Econômicos e Administrativos adotados na execução da Política Florestal

\begin{tabular}{|l|l|l|}
\hline LEGAIS & ECONÔMICOS & ADMINISTRATIVOS \\
\hline Constituição & Financiamento & Instituições \\
Emenda Constitucional & Crédito & Floresta de produção \\
Lei Complementar & Subsídio & Zoneamento \\
Código & Taxa & Sistemas de informação \\
Lei Ordinária & Imposto & Inventário Florestal Nacional \\
Medida Provisória & Fundo Florestal & Assentamento florestal \\
Resolução CONAMA & Fundo de Aval & Autorização \\
Decreto & Reposição Florestal & Licença \\
Instrução Normativa & Mudas & Concessão Florestal \\
Portaria & Insumos & \\
Ordem de Serviço & Implementos & \\
\hline
\end{tabular}

Fonte: SILVA, 2004.

Com base nesse modelo, adaptou-se, para o presente estudo, o conjunto dos instrumentos de Volta Redonda analisados (Tabela 1). 
Tabela 1 - Instrumentos de Gestão Ambiental de Volta Redonda

\begin{tabular}{l|l|l}
\hline LEGAIS & ECONÔMICOS & ADMINISTRATIVOS \\
\hline $\begin{array}{l}\text { Lei } \mathrm{n}^{\circ} 4.438 / 08 \\
\begin{array}{l}\text { Estabelecimento de parâmetros e } \\
\text { padrões de qualidade ambiental }\end{array}\end{array}$ & $\begin{array}{l}\text { Fundo Municipal de Meio } \\
\text { Ambiente } \\
\text { Mecanismos de benefícios } \\
\text { e incentivos a preservação } \\
\text { e conservação dos recursos } \\
\text { naturais }\end{array}$ & $\begin{array}{l}\text { Zoneamento } \\
\text { Criação de espaços territoriais } \\
\text { AlA } \\
\text { Licenciamento Ambiental } \\
\text { Auditoria Ambiental } \\
\text { Monitoramento Ambiental }\end{array}$ \\
& & $\begin{array}{l}\text { Fiscalização Ambiental } \\
\text { Sistema de Informações } \\
\text { Cadastro Municipal }\end{array}$ \\
& & $\begin{array}{l}\text { Conselho Municipal de Meio Ambiente } \\
\text { Conferência Municipal de Meio Ambiente } \\
\text { Agenda 21 Local }\end{array}$ \\
\hline
\end{tabular}

Fonte: Lei Municipal $n^{\circ} 4.438 / 08$

\section{MATERIAL E MÉTODOS}

As informações necessárias para a pesquisa e formulação deste artigo foram levantadas nas leis municipais de interesse ambiental e colhidas pelo pesquisador junto aos funcionários públicos dos órgãos pesquisados, em jornais da região e em sítios eletrônicos da Secretaria Municipal de Meio Ambiente, Serviço Autônomo de Água e Esgoto, Secretaria Municipal de Saúde, Secretaria Municipal de Serviços Públicos, Câmara Municipal de Volta Redonda, Instituto Estadual do Ambiente, Secretaria Estadual do Ambiente, Instituto Brasileiro do Meio Ambiente e dos Recursos Naturais Renováveis e Ministério do Meio Ambiente.

Em Volta Redonda, a participação da sociedade no processo de gestão ambiental é garantida pela existência dos instrumentos previstos na Lei Municipal $n^{\circ} 4.438 / 08$, que cria o Código Municipal de Meio Ambiente e a Política Municipal de Meio Ambiente. Nesse código, o texto legal relaciona o Conselho Municipal de Defesa do Meio Ambiente (COMDEMA/VR), a Conferência Municipal de Meio Ambiente (CMMA) e a Agenda 21 Local como fóruns democráticos de participação popular. Conforme disposto no artigo 11, da Lei Municipal ${ }^{\circ} 4.438 / 08$, o Conselho Municipal de Defesa do Meio Ambiente é composto por dezessete conselheiros, sendo seis representantes do Poder Executivo Municipal, um representante de órgão ambiental do Poder Executivo Federal ou Estadual, um representante da Câmara Municipal de Volta Redonda e oito representantes da sociedade civil, assim dispostos, dois representantes de instituições de ensino superior com unidades em funcionamento no Município, três representantes dos seguintes órgãos de controle do exercício profissional: um do Conselho Regional de Biologia - $2^{\text {a }}$ Região (CRBio-2), um do Conselho Regional de Engenharia, Arquitetura e Agronomia do Rio de Janeiro -CREA/RJ e um da Ordem dos Advogados do Brasil (OAB/RJ, $5^{\text {a }}$ subseção- Volta Redonda), um representante das Associações de Moradores, um representante do setor empresarial e um representante de sindicatos de trabalhadores do Município. O secretário de Meio Ambiente é o encarregado da presidência do conselho.

Observa-se pela formação que existe representatividade popular, garantida por uma formação plural. O mandato dos conselheiros eleitos é de dois anos a partir da data de nomeação pelo Prefeito Municipal e com término na Conferência Municipal seguinte. As reuniões ordinárias acontecem sem- 
pre na terceira quarta-feira de todo mês, na qual se discutem os problemas ambientais do município e as formas de resolução deles, levando-se em consideração o quórum mínimo e o consenso entre os conselheiros presentes.

O autor deste estudo foi conselheiro municipal de Meio Ambiente eleito por aclamação, na $2^{\text {a }}$ Conferência Municipal de Meio Ambiente, que ocorreu em maio de 2011, representando o Centro Universitário de Volta Redonda (UniFOA) e que teve como pauta a formação de um novo conselho para o biênio 2011/2012 e, atualmente, comparece às reuniões na condição de cidadão voltarredondense e pesquisador, pois não mais integra o referido conselho. Vale ressaltar que, na última reunião do ano de 2011, os conselheiros acordaram a necessidade de enviar um ofício ao Prefeito Municipal, no qual constam prioridades para o ano de 2012 e anos seguintes, cobrando a tomada de providências cabíveis, a fim de aprimorar a gestão ambiental municipal. Nesse ofício, constam as seguintes reivindicações: integração das atividades do Conselho Municipal de Meio Ambiente as atividades da Coordenadoria Municipal de Defesa Civil, tendo em vista que a cidade sofre demais com a ocorrência de movimentos gravitacionais de massa durante os meses de intensa pluviosidade (outubro a março), devido à ocupação desordenada em encostas; criação de uma ouvidoria no site da SMMA/VR para aumentar o canal de comunicação da comunidade com o órgão ambiental; projeto de lei para criação dos cargos de fiscal ambiental e analista ambiental e realização de concurso público em caráter de urgência para preenchimento das vagas a serem criadas por lei específica; retomada da Agenda 21 Local e nomeação do secretário executivo para apoio as ações do próprio conselho.

Também foi solicitada, ao Prefeito Municipal, a prestação de contas referentes ao Fundo Municipal de Conservação Ambiental (FUMCAM) e Imposto sobre Circulação de Mercadorias e Serviços (ICMS) Ecológicos recebido pelo município; criação de um espaço físico adequado para sediar as reuniões do respectivo conselho com um mobiliário adequado (mesa, cadeiras, material de escritório, computador, etc.); inclusão de um link no sítio eletrônico da Prefeitura Municipal para acesso instantâneo ao Conselho Municipal de Meio Ambiente, para facilitar o recebimento de denúncias; apoio da Prefeitura Municipal de Volta Redonda para a capacitação dos conselheiros em fóruns, congressos, encontros, seminários e para a $4^{\mathrm{a}}$ Conferência Mundial sobre Meio Ambiente, intitulada RIO +20; implementação de logística adequada para o recebimento de pilhas e baterias, medicamentos usados e vencidos e lixo eletrônico; monitoramento do ar no município para confrontação de dados com os resultados obtidos pelo INEA e CSN. Essas prioridades apontadas e solicitadas foram fruto de intensa discussão entre os conselheiros e ficou acertado que o conselho será mais proativo e cobrará mais do Poder Executivo na estruturação da Secretaria Municipal de Meio Ambiente, que apresenta carência de pessoal qualificado em sua nova estrutura organizacional, segundo o funcionário lotado nela.

Outra reunião ordinária importante do COMDEMA ocorre em 16 de julho de 2014, na qual os conselheiros presentes concordaram com a necessidade de se revisar o Código Ambiental municipal e a marcação de uma reunião com o Prefeito Municipal para expor as necessidades do conselho.. $\mathrm{Na}$ reunião do COMDEMA, de 14 de novembro de 2014, houve consenso sobre a inoperância do conselho frente aos problemas enfrentados e não resolvidos e à falta de recursos do FUMCAM para poder realizar a manutenção de veículos da Secretaria Municipal de Meio Ambiente, que poderiam potencializar a fiscalização ambiental no município.

Outro instrumento previsto no Código Municipal de Meio Ambiente de Volta Redonda que garante a participação popular no processo de gestão ambiental é a Conferência Municipal de Meio Ambiente (CMMA), definida pelo código acima como instância primordial de participação da população na defesa e preservação do meio ambiente para as atuais e futuras gerações. Conforme disposto no artigo 24, da Lei Municipal $n^{\circ} 4.438 / 08$, a referida conferência deverá garantir a maior representação possível dos segmentos sociais interessados direta ou indiretamente nos processos de promoção do 
meio ambiente ecologicamente equilibrado. 0 regimento interno de cada conferência será aprovado por todos os participantes na instalação dos trabalhos e será realizada bienalmente, convocada pela Comissão Preparatória pelo Prefeito Municipal. A Agenda 21 local é o outro instrumento previsto no artigo $4^{\circ}$, XIV, da Lei Municipal no 4.438/08, que garante a participação da sociedade no processo de gestão ambiental de Volta Redonda e que teve suas atividades encerradas. Braga (2001) ressalta que a importância da criação de órgãos colegiados de política urbana em nível local, ou seja, dos Conselhos Municipais de Desenvolvimento Urbano que, associados aos Conselhos Municipais de Meio Ambiente (e dos demais órgãos colegiados), criariam a estrutura necessária para a gestão urbana participativa, por meio das consultas populares, audiências públicas e, principalmente, as conferências municipais de desenvolvimento urbano. A lei municipal $n^{\circ} 4.441 / 08$, que instituiu o Plano Diretor em Volta Redonda, garante a participação da sociedade no processo da gestão urbana, conforme disposto em seu artigo 97 , onde se lê

a gestão urbana participativa consiste no processo democrático e transparente de negociação, decisão, corresponsabilização, ação e controle social, envolvendo os Poderes Executivo, Legislativo e a sociedade civil, em conformidade com as determinações deste Plano Diretor e dos demais instrumentos de política urbana e de planejamento e gestão municipal.

A elaboração do Plano Diretor participativo em Volta Redonda começou em 06 de junho de 2006, no auditório da Universidade Federal Fluminense (UFF), com a abertura dos trabalhos e assinatura do decreto municipal $n^{\circ} 10.585$, que cria o Grupo de Trabalho para a elaboração do Novo Plano Diretor participativo do município de Volta Redonda e que contou com a participação de 132 pessoas. 0 novo plano diretor tinha por objetivo o cumprimento do disposto na lei $n^{\circ} 10.257 / 01$ (Estatuto da Cidade), que estabelece a obrigatoriedade de um plano diretor para os municípios com mais de 20.000 habitantes.

Havia igualmente a necessidade de substituição do Plano Estrutural de Desenvolvimento Integrado de Volta Redonda (PEDI/VR), que foi aprovado em 1976, e que não atendia mais as necessidades locais. Após a abertura dos trabalhos, foram realizadas nove reuniões em vários pontos da cidade, onde foram discutidos vários assuntos, entre eles a importância do plano diretor, os pontos negativos e positivos do município, leitura da cidade e, como produto final, a feitura do diagnóstico da cidade, a partir das contribuições dos participantes (Instituto de Pesquisa e Planejamento Urbano/IPPU/VR, Secretaria Municipal de Planejamento/SMP, Empresa de Processamento de Dados/EPD/VR, Secretarias Municipais, Autarquias, Empresas de Economia mista, Fundações, acadêmicos, Conselhos de Classe, ONGs, movimento sindical, movimentos populares, Agenda 21, entidades empresariais e movimentos da juventude). Nessas nove reuniões realizadas, os temas prioritários eleitos para nortear os trabalhos versaram sobre: imagem da cidade, função e papel econômico, expansão/adensamento, mobilidade, sustentabilidade e questões ambientais, que foram amplamente discutidas. Os mais diversos problemas ambientais foram mencionados nas reuniões como, por exemplo: o baixo índice de tratamento de esgoto $\left(2^{\mathrm{a}}, 5^{\mathrm{a}} \mathrm{e}\right.$ $7^{\mathrm{a}}$ plenárias), as áreas protegidas existentes ( $2^{\mathrm{a}}$ plenária), falta de ciclovias $\left(2^{\mathrm{a}}, 3^{\mathrm{a}}, 4^{\mathrm{a}}\right.$ e $5^{\mathrm{a}}$ plenárias), aterro sanitário ( $2^{\mathrm{a}}$ e $8^{\mathrm{a}}$ plenárias), margens do rio Paraíba do Sul ( $3^{\mathrm{a}}$ e $6^{\mathrm{a}}$ plenárias), poluição do meio ambiente $\left(3^{a}, 5^{a}, 6^{a}, 7^{a}\right.$ e $9^{a}$ plenárias), arborização urbana ( $4^{a}$ e $7^{a}$ plenárias), poluição dos rios ( $5^{a}$ e $7^{\text {a }}$ plenárias), falta de conscientização da população sobre lixo, posturas e civilidade ( $5^{a}$ plenária), desmatamento de encostas ( $5^{\mathrm{a}}$ plenária), crescimento desordenado e ocupação de encostas e margens de corpos hídricos $\left(5^{a}, 7^{a}\right.$ e $8^{a}$ plenárias), sustentabilidade ( $6^{a}$ plenária), ausência de áreas verdes ( $7^{\mathrm{a}}$ plenária), descaso com afluentes ( $8^{a}$ plenária) e lixo lançado nas águas e margens ( $8^{\mathrm{a}}$ plenária). Após a realização das nove reuniões, aconteceu, no dia 18 de julho de 2006, o fórum de diagnóstico da cidade, que teve como ponto alto a apresentação da Superintendência de Serviços Rodoviários (SUSER), sobre o plano de transportes em estudo, e a apresentação do Serviço Autônomo de Água e Esgoto/SAAE/VR, sobre o abastecimento de água e esgoto no município. 
As plenárias (nove reuniões) para a apresentação das proposições retiradas dos encontros começaram no dia 20 de julho de 2006 e a primeira discussão teve sede no auditório do Serviço Social da Indústria (SESI), onde foram divididos os novos temas prioritários (Desenvolvimento Urbano e Infraestrutura, Desenvolvimento Econômico, Trânsito, Transporte e Mobilidade, Saneamento Ambiental, Habitação e Uso do solo e terras ociosas) e seus respectivos grupos de trabalho, com vistas a pactuação a serem inseridas no novo plano diretor. 0 clube dos Funcionários da CSN sediou o fórum de pactuação de propostas, que aconteceu no dia 22 de agosto de 2006, onde foi feita a leitura das propostas pactuadas pelos relatores dos grupos de trabalho anteriormente definidos.

No ano de 2008, o Plano Diretor foi, enfim, aprovado e instituído pela Lei Municipal no 4.441/08, que em seu título "aprova o Plano Diretor participativo de desenvolvimento urbano de Volta Redonda e dá outras providências". O Plano Diretor municipal descreve os seguintes mapeamentos relacionados ao meio ambiente: Redes de Água, Esgoto e Drenagem; Histórico da Ocupação; Limitações à Ocupação Urbana; Bacias e Sub-Bacias Hidrográficas. Existem restrições à ocupação das Zonas de Especial Interesse Social (ZEIS), nas seguintes condições:

\author{
I. de preservação ambiental ou histórico-cultural; \\ II. que apresentem risco à saúde ou à vida; \\ III. que apresentem risco de moradia ou ao meio ambiente natural; \\ IV. situadas nas proximidades de aterros ou depósitos de lixo; \\ V. localizadas nas faixas de domínio público das rodovias, ferrovias e dutos, conforme disposto no inciso Il, artigo \\ $4^{\circ}$, da Lei Federal nº 6.766/79; \\ VI. situadas nas Zonas de Preservação Ambiental, conforme definição dessa Lei; \\ VII. onde as condições do solo não permitam a edificação ou o parcelamento; \\ VIII. que a degradação ambiental impeça condições sanitárias suportáveis.
}

Vê-se, portanto, que o Plano diretor contempla diversos instrumentos de política ambiental (art. 21) e tem mapeadas as áreas de utilização e conservação dos recursos naturais, as áreas destinadas a unidades de conservação, as zonas a serem protegidas (art. 51), a compatibilização do planejamento territorial com o diagnóstico ambiental e a previsão de elaboração do Plano Municipal de Meio Ambiente (art. 64, IX).

É importante destacar que o Plano Diretor não prevê a existência de definições relativas ao orçamento municipal como a determinação de prioridades de investimentos ou a definição de obras e investimentos concretos na área ambiental. Prevê apenas dois instrumentos e mecanismos de controle social na política de meio ambiente. A redação do artigo 64 , VII, trata do direcionamento do processo de formação de consciência crítica na população, procurando nortear a sua relação com o meio ambiente, e o artigo 73 faz menção à implantação de mecanismos de controle social sobre todos os serviços prestados no âmbito do saneamento ambiental.

\title{
4 RESULTADOS E DISCUSSÃO
}

Como bem acentua Scardua (2003), há a obrigação de se rever os métodos de participação e representação popular, tendo em vista que mesmo prevista em lei, não é suficiente para garantir o controle social. É visível também a necessidade de criação de um programa de capacitação para seus representantes e de proceder a uma revisão do próprio SISNAMA.

O envolvimento da população em Volta Redonda com a questão ambiental é muito incipiente e não resulta na melhoria de sua qualidade de vida, seja pela sua passividade como também pela falta 
de cobrança aos órgãos públicos para a solução de problemas ambientais existentes. O SISMUMA/VR não divulga os resultados existentes (autos de infração aplicados, fiscalização ambiental promovidas, dados de monitoramento do controle da poluição atmosférica, audiências públicas para o licenciamento de atividades poluidoras, ações de educação ambiental formal e não formal realizadas, etc.) no site da secretaria e que também não é atualizado com freqüência (as notícias veiculadas são de 2010).

As pesquisas realizadas também apontam que o Poder Público Municipal não fomenta a participação da sociedade no processo de gestão ambiental, pois inexistem canais diretos visíveis para comunicação de ocorrências ambientais. No sítio eletrônico da Prefeitura Municipal de Volta Redonda não se observa nenhum link que chame a atenção do munícipe para a área ambiental e tampouco são divulgadas as datas de reunião do Conselho Municipal de Meio Ambiente para os demais cidadãos. $\mathrm{Na}$ cidade de Volta Redonda, existem diversos outdoors eletrônicos da Prefeitura em pontos estratégicos, onde poderiam ser divulgados os telefones de contato do órgão ambiental para denúncias e eventos relacionados à proteção do meio ambiente. Maglio (2000) frisa que, para a evolução de uma sociedade governada por "representantes" para um sistema no qual há participação direta do cidadão, é fundamental um novo estilo de organização, por meio da criação de mecanismos de participação na gestão, mecanismos de comunicação e informação, reafirmando a fundamental importância das formas de controle direto, representadas pela construção de conselhos de gestão ambiental atuantes e de comitês de bacia hidrográfica. A retomada da Agenda 21 local também é condição sine qua non para que se ampliem os espaços para discussão da problemática ambiental em Volta Redonda.

Vale também ressaltar que o órgão ambiental municipal não realiza audiências públicas para se discutir os impactos ambientais locais, como o licenciamento de hipermercados e shoppings, que resultam em profundas modificações na qualidade de vida das pessoas que residem na circunvizinhança. A pesquisa também aponta o baixo grau de percepção ambiental e participação da população voltarredondense acerca dos inúmeros problemas ambientais existentes que a atingem e que corroboram para a degradação dos recursos ambientais e para a diminuição de sua qualidade de vida. A consumação dessa situação de omissão da sociedade é fato preocupante, pois a mola propulsora de mudanças é a ação , pressionando os órgãos públicos para a adoção de medidas tempestivas, corretivas, fiscalização, planejamento e também o aperfeiçoamento de suas tarefas rotineiras com vistas à prática do desenvolvimento sustentável local.

O artigo 225 da Carta Maior é claro e apregoa a necessidade da coletividade e do Poder Público agirem juntos na proteção do meio ambiente ecologicamente equilibrado. Atualmente, a população de Volta Redonda só se faz representar no Conselho Municipal de Meio Ambiente, órgão colegiado deliberativo que se reúne mensalmente para debater os problemas ambientais existentes, propor soluções e traçar estratégias. Percebe-se também que o Plano Diretor reflete os anseios da população e dos planejadores públicos e que se faz necessário implementar integralmente a Política Municipal de Meio Ambiente, entendida como um conjunto de diretrizes, instrumentos e mecanismos de política pública que, além de orientar a gestão ambiental municipal, promoverá a preservação, a utilização racional e adequada dos recursos naturais renováveis e não renováveis e comprometer-se-á obrigatoriamente com a conservação sistemática e permanente dos ambientes naturais relevantes (artigo $62, \S 1^{\circ}$ do Plano Diretor de Volta Redonda).

\section{CONSIDERAÇÕES FINAIS}

Nessa seara, será imprescindível "provocar" a sociedade voltarredondense a assumir seu papel de agente indispensável à materialização da gestão ambiental pública e descentralizada, visando a sua contribuição através de reuniões em associações de moradores, reuniões do Conselho Municipal de 
Desenvolvimento Urbano, do orçamento participativo, do Conselho Municipal de Meio Ambiente, audiências públicas para licenciamento ambiental, denúncias aos órgãos ambientais e Ministério Público Estadual e Federal e participação na Agenda 21 local.

O Conselho Municipal de Meio Ambiente, que é consultivo e deliberativo, precisa ser mais proativo e enérgico para deliberar assuntos de interesse ambiental, cobrar efetivamente da Secretaria Municipal de Meio Ambiente as medidas cabíveis discutidas nas reuniões ordinárias e extraordinárias que objetivam o aperfeiçoamento da gestão ambiental pública. Nesse ínterim, também seria imprescindível acionar o Ministério Público Estadual e Federal para fortalecer o pacto social e potencializar as ações do COMDEMA/VR.

Há falta de uma política ambiental indutora de mudanças comportamentais com o uso de instrumentos econômicos - adotada em vários municípios e estados, inclusive no Rio de Janeiro - para incentivar a proteção de recursos naturais, a exemplo do pagamento por serviços ambientais do município de Extrema/MG, que remunera os proprietários que conservam, em sua propriedade rural, nascentes estratégicas para a bacia hidrográfica a ser manejada.

A pesquisa permite também concluir que é baixo o grau de percepção ambiental e participação da população voltarredondense na discussão dos muitos problemas ambientais existentes que a atingem e que corroboram para a degradação dos recursos ambientais e diminuição de sua qualidade de vida. 


\section{REFERÊNCIAS}

AGENDA 21 BRASILEIRA: resultado da consulta nacional/Comissão de Políticas de Desenvolvimento Sustentável e da Agenda 21 nacional. 2. ed. Brasília: Ministério do Meio Ambiente. 2004. 158p.

BRAGA, R. Gestão Ambiental no Estatuto da Cidade: alguns comentários. In: Perspectivas de Gestão Ambiental em Cidades Médias. CARVALHO, P. F. de e BRAGA, R. (orgs.), Rio Claro, LPM-UNESP. 2001, pp. 95-119.

BRASIL. Lei Federal nº 6.938/81. Política Nacional do Meio Ambiente, 1981. Brasília. Distrito Federal.

Lei Federal nº 7.347/85. Ação Civil Pública, 1985. Brasília. Distrito Federal.

Constituição Federal de 05 de outubro de 1988. Brasília. Distrito Federal.

Lei Federal n 9.605/98. Lei de Crimes Ambientais, 1998. Brasília. Distrito Federal.

Lei Federal $n^{\circ}$ 10.257/01. Estatuto da Cidade, 2001. Brasília. Distrito Federal.

Ministério do Meio Ambiente. Disponível em: <www.mma.gov.br>. Acesso em: 22 jul. 2016.

BUARQUE, S. C. Construindo o desenvolvimento local sustentável: metodologia de planejamento. Rio de Janeiro: Ed. Garamond, 2002. 177p.

GURGEL JÚNIOR, F. J. Gestão ambiental municipal: estudo de caso de Volta Redonda/RJ, no período 2005-2012. 149p. Tese (Doutorado) Universidade Federal Rural do Rio de Janeiro, 2012.

IBGE. Instituto Brasileiro de Geografia e Estatística. Disponível em: <www.ibge.gov.br>. Acesso em: 20 jul. 2016.

. Instituto Brasileiro de Geografia e Estatística. Perfil dos Municípios Brasileiros. Rio de Janeiro. 2008. 244p.

IBAMA. Instituto Brasileiro do Meio Ambiente e dos Recursos Naturais Renováveis. Disponível em: <www.ibama.gov.br>. Acesso em: 19 jul. 2016.

INEA. Instituto Estadual do Ambiente do Rio de Janeiro. Disponível em: <www.inea.rj.gov.br>. Acesso em: 06 jul. 2016.

GOVERNO DO ESTADO DO RIO DE JANEIRO. Secretaria Estadual de Meio Ambiente do Rio de Janeiro. Disponível em: <www.sea.rj.gov.br>. Acesso em: 23 jul. 2016.

Lei Municipal $n^{\circ}$ 4.438/08. Dispõe sobre a criação do Código Municipal de Meio Ambiente de Volta Redonda. Volta Redonda/RJ.

Lei Municipal, $\mathbf{n}^{\circ}$ 4.441/08. Aprova o Plano Diretor Participativo de Desenvolvimento Urbano de Volta Redonda e dá outras providências. Volta Redonda/RJ.

MACHADO, P. A. L. Direito Ambiental brasileiro. 18. ed. São Paulo: Editora Malheiros, 2010. 1177p. 
MAGLIO, I. C. A descentralização da Gestão Ambiental no Brasil: o papel dos órgãos estaduais e as relações com o poder local, 1990/1999. Dissertação de Mestrado - Faculdade de Saúde Pública da USP. 2000. São Paulo. 283p.

MILARÉ, É. Direito do Ambiente: a gestão ambiental em foco. Editora Revista dos Tribunais. $6^{a}$ Edição. 2009. São Paulo. 1343p.

PHILIPPI JR. A.; ROMÉRO, M. A.; BRUNA, G. C. Curso de Gestão Ambiental. Barueri/SP. Manole, 2004.

PMVR. Prefeitura Municipal de Volta Redonda. Disponível em: <www.portalvr.com.br $>$. Acesso em 14 jul. 2016.

RESOLUÇÃO CONAMA n 001/86. Dispõe sobre critérios básicos e diretrizes gerais para o Relatório de Impacto Ambiental-RIMA, 1986. Brasília/DF.

n²37/97. Dispõe sobre o licenciamento ambiental, 1997. Brasília/DF.

SABOYA, R. T. de. Planos Diretores como instrumento de integração da gestão e do planejamento urbanos. In: Congresso Brasileiro de Cadastro Multifinalitário. Florianópolis/SC. 15 à 19 de outubro de 2006. 8p.

SAAEVR. Serviço Autônomo de Água e Esgoto de Volta Redonda. Disponível em: <www.saaevr.com. br>. Acesso em: 21 jul. 2016.

SANTOS, R. F. Planejamento ambiental: teoria e prática. São Paulo: Editora Oficina dos Textos, 2004.

SCARDUA, F. P. Governabilidade e descentralização da gestão ambiental no Brasil. Tese de Doutorado. Brasília/DF. Universidade de Brasília. Centro de Desenvolvimento Sustentável. 2003. 234 p.

SILVA, J. de A. Notas de aula do Curso de Graduação em Engenharia Florestal da UFRRJ e do Curso de Pós-Graduação em Ciências Ambientais e Florestais. Disciplinas: Política, Legislação e Administração Florestal; Política e Gestão Florestal. 2004. 